\title{
Compaction, compression and drug release properties of diclofenac sodium and ibuprofen pellets comprising xanthan gum as a sustained release agent
}

\author{
Helton Santos*, Francisco Veiga, Mª Eugénia Pina, João J. Sousa \\ Centro de Estudos Farmacêuticos, Faculdade de Farmácia, Universidade de Coimbra, Rua do Norte, 3000295 Coimbra, Portugal
}

Received 18 June 2004; received in revised form 5 January 2005; accepted 6 January 2005

Available online 17 March 2005

\begin{abstract}
Compaction and compression of xanthan gum pellets were evaluated and drug release from tablets made of pellets was characterised. Two types of pellets were prepared by extrusion-spheronisation. Formulations included xanthan gum, at $16 \%(\mathrm{w} / \mathrm{w})$, diclofenac sodium or ibuprofen, at 10\% (w/w), among other excipients. An amount of $500 \mathrm{mg}$ of pellets fraction 1000-1400 $\mu \mathrm{m}$ were compacted in a single punch press at maximum punch pressure of $125 \mathrm{MPa}$ using flat-faced punches (diameter of $1.00 \mathrm{~cm}$ ). Physical properties of pellets and tablets were analysed. Laser profilometry analysis and scanning electron microscopy of the upper surface and the surface of fracture of tablets revealed that particles remained as coherent individual units after compression process. Pellets were flatted in the same direction of the applied stress evidencing a lost of the original curvature of the spherical unit. Pellets showed close compressibility degrees (49.9\% for pellets comprising diclofenac sodium and $48.5 \%$ for pellets comprising ibuprofen). Xanthan gum pellets comprising diclofenac sodium experienced a reduction of $65.5 \%$ of their original sphericity while those comprising ibuprofen lost $49.6 \%$ of the original porosity. Permanent deformation and densification were the relevant mechanisms of compression. Fragmentation was regarded as non-existent. The release of the model drug from both type of tablets revealed different behaviours. Tablets made of pellets comprising ibuprofen released the model drug in a bimodal fashion and the release behaviour was characterised as Case II transport mechanism (release exponent of 0.93). On the other hand, the release behaviour of diclofenac sodium from tablets made of pellets was anomalous (release exponent of 0.70 ). For the latter case, drug diffusion and erosion were competing mechanisms of drug release.
\end{abstract}

(c) 2005 Elsevier B.V. All rights reserved.

Keywords: Pellets; Extrusion-spheronisation; Compaction; Compression; Drug release; Diffusion; Erosion

\footnotetext{
* Corresponding author. Tel.: +351 239855080 ; fax: +351239855099.

E-mail address: helton@ci.uc.pt (H. Santos).
}

\section{Introduction}

The design and development of multiparticulate dosage formulations in the form of tablets has been of great interest to the pharmaceutical engineering as an 
attempt to overcome the high costs involved in the production of encapsulated dosages (Çelik, 1994). Many investigations evaluated the mechanisms involved during compaction of regular and irregular shaped multiunits in order to overcome the costs involved in the production of hard capsule dosage forms (Johansson et al., 1995, 1998; Johansson and Alderborn, 1996, 2001; Wikberg and Alderborn, 1990a,b, 1991, 1992a,b, 1993).

It is suggested that four mechanisms are involved in the compression process of granules namely, deformation, densification, fragmentation and attrition (Çelik, 1994; Johansson et al., 1995). Owing to the irregular shape and to the surface roughness of granules, it is rather difficult to determine the degree of incidence of the suggested mechanisms. Recently, the use of nearly spherical units, here defined as pellets, brought new light into the mechanistic knowledge of the compaction process of porous particles and justified the use of these units as an alternative model system (Johansson et al., 1995). It has been suggested that permanent deformation and densification are the mechanisms involved in the compression of spherical units while fragmentation and attrition seem to be inexistent or to occur to a minute extent (Johansson et al., 1995, 1998; Johansson and Alderborn, 1996, 2001).

The general purpose of this study was to investigate the effect of the physical properties (shape, surface roughness, specific surface area, tensile strength, porosity and pore structure) of pellets on their compression behaviour and tablet forming ability (Johansson et al., 1995, 1998; Johansson and Alderborn, 1996, 2001; Wikberg and Alderborn, 1990a,b, 1991, 1992a,b, 1993; Nicklasson et al., 1999a,b). The specific purpose was to investigate the influence of the physico-chemical properties of the model drug on the physical characteristics of pellets comprising a hydrophilic polymer intended for sustained release. For that purpose, two types of pellets were prepared both comprising xanthan gum as the hydrophilic polymer and one of two different active drugs in their formulations. Pellets were also assessed for the degree of compression and densification and tablets made of pellets were considered for the determination of the tensile strength, total porosity, appearance of the upper and fracture surfaces, in an attempt to add and/or confirm knowledge to the compression mechanism of nearly spherical units formed from other materials than microcrystalline cellulose (Johansson et al.,
1995, 1998; Johansson and Alderborn, 1996, 2001) or binary mixtures of microcrystalline cellulose and filler (Nicklasson et al., 1999a,b). Specifically, this work intended to answer whether pellets prepared by the extrusion and spheronisation process and differing on the type of one of their ingredients would differ on the compaction behaviour, drug release and dissolution behaviour of the tablets.

The hydrophilic polymer xanthan gum is a high molecular weight heteropolysaccharide gum produced by a pure culture fermentation of a carbohydrate with the microorganism Xanthamonas campestris. It has been widely used in oral and topical formulations, cosmetics and food as suspending or stabilising agent, and release control agent in hydrophilic matrix formulations (Talukdar and Plaizier-Vercammen, 1993; Wade and Weller, 1994; Talukdar et al., 1996a,b; Ingani and Moës, 1998). Furthermore, xanthan gum proved to have higher drug-retarding ability than the wellknown hydroxypropylmethyl cellulose (Talukdar et al., 1996a,b; Talukdar and Kinget, 1997).

\section{Materials}

Diclofenac sodium (mean particle diameter $20.96 \mu \mathrm{m}$ ) and ibuprofen (mean particle diameter $77.97 \mu \mathrm{m}$ ) were purchased from Capsifar Lda, Oeiras, Portugal and Farmachem S.A., Lugano, Switzerland, respectively, and were used as model drugs. Xanthan gum, purchased from Capsifar Lda, Oeiras, Portugal, was employed as the matrix former excipient. Microcrystalline cellulose powder (Microcel ${ }^{\circledR}$ 101) obtained from Sagran, Milan, Italy, was the support excipient. Lactose monohydrate (Granulac ${ }^{\circledR}$ 200, Meggle, Wasserburg, Germany) was used as filler. Povidone (Kolidon ${ }^{\circledR}$ K30, BASF) was employed as a secondary binder. All the materials were used as received without further treatment. The granulation liquid was a solution $(50 \%, \mathrm{v} / \mathrm{v})$ consisting of distilled water and ethanol 95\% (commercial grade).

\section{Methods}

The determination of the particle size of the active drugs (diclofenac sodium and ibuprofen) was carried out in a Malvern Master Sizer (Series 2600C, Malvern 
Instruments Ltd., Malvern, UK). The mean values for the particle diameter by volume are presented (mean of three determinations).

Two pellets formulations were prepared. Formulations were based in microcrystalline cellulose, $50 \%$ (w/w); model drug, $10 \%(\mathrm{w} / \mathrm{w})$; xanthan gum as the control release agent, $16 \%(\mathrm{w} / \mathrm{w})$; povidone as a secondary binder, $8 \%(\mathrm{w} / \mathrm{w})$; and lactose monohydrate, $16 \%(\mathrm{w} / \mathrm{w})$. Pellet formulation $1 \mathrm{~A}$ (PF\#1A) comprised diclofenac sodium, while pellet formulation $1 \mathrm{~B}$ (PF\#1B) comprised Ibuprofen. Pellets were prepared by extrusion-spheronisation employing ethanol/water mixture $50 \%(\mathrm{v} / \mathrm{v})$ as the binding liquid according to previous works (Santos et al., 2002, 2004). Dry powder mixtures, not including povidone, were blended in a planetary mixer for $20 \mathrm{~min}$. Povidone was included in the formulations as a solution in the binding liquid. The appropriate total quantity of the binding liquid, which gave the suitable wet mass for extrusion thus the best pellets in terms of roundness (visual inspection), was determined by trial and error. The wet masses were extruded in a screen extruder (Caleva model 10, Dorset, England) equipped with a standard screen $1 \mathrm{~mm}$ diameter apertures, and rolls rotating at $60 \mathrm{rpm}$. The extrudates were transferred to the spheroniser (Caleva model 250, Dorset, England) equipped with a crosshatch plate $(250 \mathrm{~mm}$ diameter $)$ and processed at $1000 \mathrm{rpm}$ rotating speed. The resultant pellets were dried during $20 \mathrm{~min}$ in a fluid bed processor (Uni-Glatt, Glatt GmbH, Binzen, Germany) with the inlet air flow at $50^{\circ} \mathrm{C}$. The characterisation of the pellets was performed on the $1000-1400 \mu \mathrm{m}$ sieve fraction obtained by dry sieving using a set of standard sieves (DIN/ISO 3310-1, Retsch, F. Kurt Retsch GmbH \& Co. Haan, Germany) following a $\sqrt{ } 2$ progression from 500 to $2000 \mu \mathrm{m}$ of sieve openings. Sieve shaker (AS 200 Control "g", Retsch, F. Kurt Retsch GmbH \& Co., Haan, Germany) operated during 15 min with an oscillation height of $1.5 \mathrm{~mm}$.

The apparent particle density of the pellets was determined using a gas pycnometer (Multipycnometer, Quantachrome Co., UK) with helium as the test gas $(n=3)$. Porosity parameters (intrusion/extrusion isotherms, pore size distribution, pore surface area and mean pore diameters) and effective particle density were assessed using mercury porosimetry (PoreSizer 9320, Micromeritics, Norcross, GA, USA) $(n=3)$. The relationship between the intruded volume of mercury and the intrusion pressure was analysed. The intrusion pressure ranged from 0.01 to $208 \mathrm{MPa}$. The pore sizes corresponding to the intrusion pressures were calculated assuming cylindrical pores and a surface tension for mercury of $485 \mathrm{mN} / \mathrm{m}$. The mercury/material advancing and receding contact angles were $130^{\circ}$. The intragranular porosity of pellets $(\varepsilon)$ was calculated according to Eq. (1)

$$
\varepsilon=1-\frac{\text { effective pellets density }}{\text { apparent pellets density }}
$$

The tensile strength of pellets $\left(\sigma_{f(s)}\right)$ of the different formulations was assessed using a universal testing instrument equipped with a $5 \mathrm{~kg}$ load cell (CT-5, Engineering Systems, Nottingham, UK). The pellets were strained until failure occurred. The load was recorded and the tensile strength was calculated applying the values of the failure load $(F)$ and the radius of the pellet $(R)$ according to Eq. (2) (Shipway and Hutchings, 1993; Salako et al., 1998) $(n=50)$

$\sigma_{f(s)}=\frac{0.4 F}{\pi R^{2}}$

Size and shape of the pellets were concomitantly derived using an image analysis system (Seescan solitaire 512, Seescan, Cambridge, UK) connected to a black and white camera (CCD-4 miniature video camera module, Rengo Co. Ltd., Toyohashi, Japan), zoom lens (18-108/2.5, Olympus Co., Hamburg, Germany), and top position cold light source (Olympus Co., Hamburg, Germany). Feret diameter and shape factor $e_{R}$ were derived from image analysis and used for statistical analysis. Shape factor $e_{R}$ is based on a twodimensional outline analysis and considers both the geometrical shape and the surface texture of the agglomerate (Podczeck and Newton, 1994). For the shape factor $e_{R}$ a value of unity considers a perfect spheroid even though a value close to 0.6 describes a particle of good sphericity. One hundred pellets of each formulation were analysed.

Surface of pellets was analysed by applying a non-contacting laser profilometer (UBM Microfocus Measurement System, UBM Messtechnik GmbH, Ettlingen, Germany). The roughness parameters were determined using the UBSOFT software which also provided a three-dimensional profile of the surface of the analysed particle. The laser spot size was of $1 \mu \mathrm{m}$, the aperture angle $53^{\circ}$, and the scanning 
speed 100 points/s. The measured area was a square of $0.25 \mathrm{~mm} \times 0.25 \mathrm{~mm}$ dimension with a resolution of 500 points $/ \mathrm{mm}$ in both the $X$ - and $Y$-directions. The Rtm (mean peak to valley ratio) parameter derived from the surface roughness measurements was used for the statistical analysis. It describes the arithmetic average of the largest height difference, each equivalent to the sum of the largest peak and the deepest valley derived from the line scan of a surface profile in each of 25 rectangles obtained by splitting the surface into a $5 \times 5$ grid. This parameter provides information about the surface that a two-dimensional line scan would not detect. Six pellets of each formulation were analysed.

Pellets were analysed applying the BET technique for the determination of the specific surface area using gas adsorption with nitrogen as the adsorbate gas (ASAP 2000, Micromeritics, Norcross, USA). Determination applied the BET model to the equilibrium isotherm within pressures of $0.05-0.30$ psia. Six experimental points (BET multipoint) was used for calculation. Samples were outgassed applying vacuum at room temperature during $24 \mathrm{~h}$ prior to the determination of the specific surface area. Three samples of each pellet formulation were analysed.

Unlubricated pellets were compressed using a single punch press (Speca Press - Automatic Press, Speca Limited, Kent, England) at maximum developed punch pressure of $125 \mathrm{MPa}$. Press was equipped with flatfaced punches of $1.00 \mathrm{~cm}$ diameter. Punches and die were lubricated before every compaction with magnesium stearate suspension $(1 \%(\mathrm{w} / \mathrm{w})$ in ethanol). An amount of $500 \mathrm{mg}( \pm 0.5)$ sample of pellets of size fraction 1000-1400 $\mu \mathrm{m}$ were accurately weighed and manually filled into the die. The prepared tablets were stored in a diseccator at room temperature for at least $48 \mathrm{~h}$ before any characterisation in order to remove any residual humidity.

Tablets of unlubricated pellets were gently shook in a Petri dish. The deaggregated pellets obtained were passed through a standard sieve of $1000 \mu \mathrm{m}$ diameter apertures (DIN/ISO 3310-1, Retsch, F. Kurt Retsch GmbH \& Co. Haan, Germany). The pellets retained in the sieve (retrieved pellets) were collected and subjected to characterisation.

The degree of compression of the pellets was calculated by applying Eq. (3) (Johansson and Alderborn, 1996). Where, $H_{0}$ is the estimated height of pellet bed in-die before compression derived from the poured bulk density and fill weight of the pellets, and the die diameter. $H_{\mathrm{p}}$ is the height of the compact. The poured bulk density of the pellets was determined in a $250 \mathrm{~mL}$ glass cylinder (inner diameter of $3.5 \mathrm{~cm}$ )

$C_{\%}=\frac{H_{0}-H_{\mathrm{p}}}{H_{0}} \times 100$

Tablets were compressed diametrically in a material testing machine (Erweka TBH28, Erweka Apparatebau $\mathrm{GmbH}$, Bizen, Fed. Rep. of Germany) at a compression rate of $5 \mathrm{~mm} / \mathrm{min}$. The tensile strength of the tablets $(\sigma)$ was calculated according to Fell and Newton (1970) (Eq. (4)) by applying the force needed to fracture the tablet $(P)$ and the diameter $(D)$ and thickness $(T)$ of the tablet. Ten tablets of each pellet formulation were analysed

$\sigma=\frac{2 P}{\pi D T}$

The total porosity $\left(\varepsilon_{\text {Total }}\right)$ of the tablets was calculated by applying the bulk density of the compact and the apparent particle density of the powder mixture. The bulk density of the tablets was derived from the dimensions and weight of the compacts, and the apparent particle density of the pellets.

The upper surface of the tablets was analysed by applying a non-contact laser profilometer (LaserScan profilometer, Solarius Development Inc., California, USA). The LaserScan is a surface profilometer for 3D laser measurement and was equipped with a confocal point sensor (LT8010, LaserScan profilometer, Solarius Development Inc., California, USA) that consisted of a laser spot size of $2 \mu \mathrm{m}$ and stand-off of $5 \mathrm{~mm}$. The laser sensor had a measuring range of $6 \mu \mathrm{m}$, and vertical resolution of $0.1 \mu \mathrm{m}$. The two- and threedimensions representations of the upper surface of the tablets were derived by using the LaserScan software (LaserScan profilometer, Solarius Development Inc., California, USA). The measured area of the upper surface of the tablets was a square of approximately $4.00 \mathrm{~mm} \times 4.00 \mathrm{~mm}$ dimension.

Photomicrographs of the pellets and the upper and fracture surfaces of the tablets were taken with a scanning electron microscope (SEM) (Philips XL20, Philips, Eindhoven, The Netherlands) for visual inspection of the shape and the surface texture of the units before and after compaction, and their mode of compaction. 
In vitro dissolution tests were performed according to the USP paddle method using a dissolution apparatus (VK 7000 dissolution testing station, Vankel, Essex, England). The test employed $1000 \mathrm{~mL}$ of phosphate buffer $\mathrm{pH} 7.4$ at $37^{\circ} \mathrm{C}$ as the dissolution medium and paddles rotating at $100 \mathrm{rpm}$. Sink conditions were kept through out the test. Samples were continuously collected and analysed by UV-Visible spectrophotometer (UV-1603 Shimadzu, Shimadzu Co., Kyoto, Japan) at $277.5 \mathrm{~nm}$ for diclofenac sodium and $265 \mathrm{~nm}$ for ibuprofen every $15 \mathrm{~min}$ over $24 \mathrm{~h}$. Pellets and tablets were analysed in triplicate.

\section{Results and discussion}

\subsection{Characterisation of pellets}

Physical characteristics of the pellets comprising either diclofenac sodium or ibuprofen as the model drug are presented (Table 1). Both types of active pellets were regarded as of good sphericity even though they exhibited shape factor $e_{R}$ not higher than 0.6 but close to this value. Such information was granted by visual assessment (Fig. 1). The surface of the pellets was smooth as observed in SEM micrographs nevertheless, the difference between the surface roughness parameter derived from the laser profilometry analysis for both formulations were statistically significant $(P=0.036, \alpha=0.05)$. Such difference could be explained in terms of the particle size of the active ingredients. Comparatively, xanthan gum pellets comprising diclofenac sodium were slightly more spherical, although no statistical difference between the two types of pellets was noticed $(P=0.341, \alpha=0.05)$, and displayed a less rough surface. The difference of resistance against fracture, expressed as the tensile strength, between the two types of pellets was statistically significant $(P<0.001, \alpha=0.05)$. Analysis of the pore structure of the pellets revealed that both types of units exhibited a sharp peak of pore size distribution in the range of macropores (Fig. 2). The mean pore diameter by volume (defined as the pore diameter at which $50 \%$ of the total volume of intruded mercury is intruded), which is greatly affected by the number of large pores, was smaller for pellets comprising ibuprofen. In that case, the total pore volume and area were higher compared to

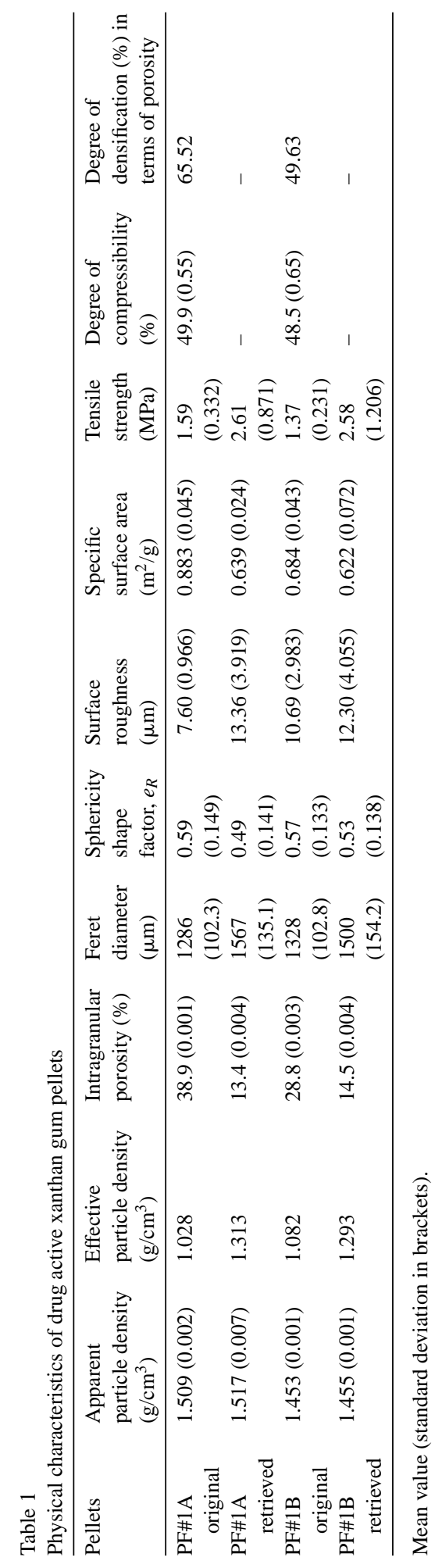




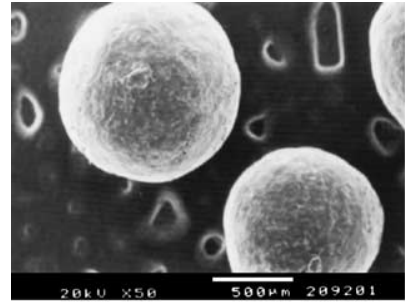

(A)

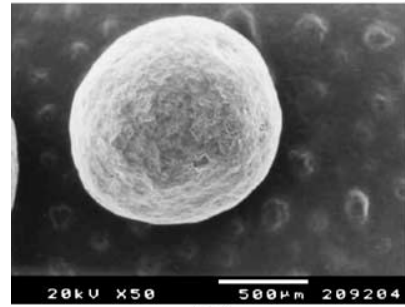

(D)

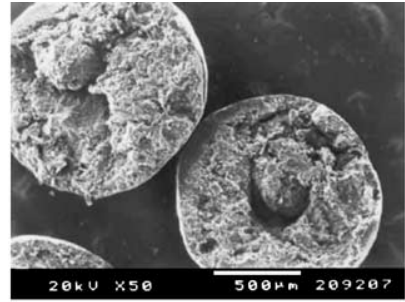

(B)

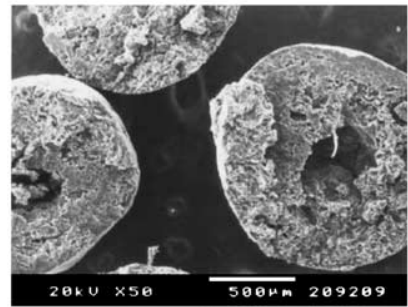

(E)

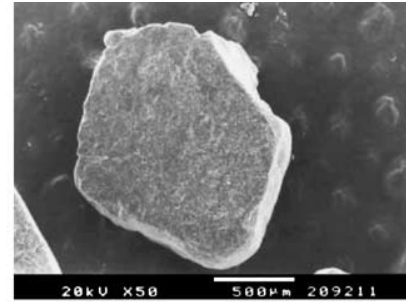

(C)

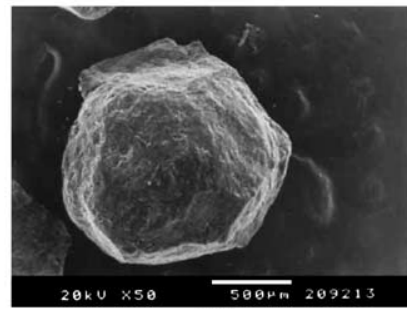

(F)

Fig. 1. SEM microphotographs of xanthan gum pellets at 50× magnification - (A) PF\#1A; (B) cross-section of pellet PF\#1A; (C) retrieved pellet PF\#1A; (D) PF\#1B; (E) cross-section of pellet PF\#1B; (F) retrieved pellet PF\#1B. White bars denote $500 \mu \mathrm{m}$.

those presented by diclofenac sodium xanthan gum pellets. These features indicated a great number of small pores for xanthan gum pellets comprising ibuprofen.

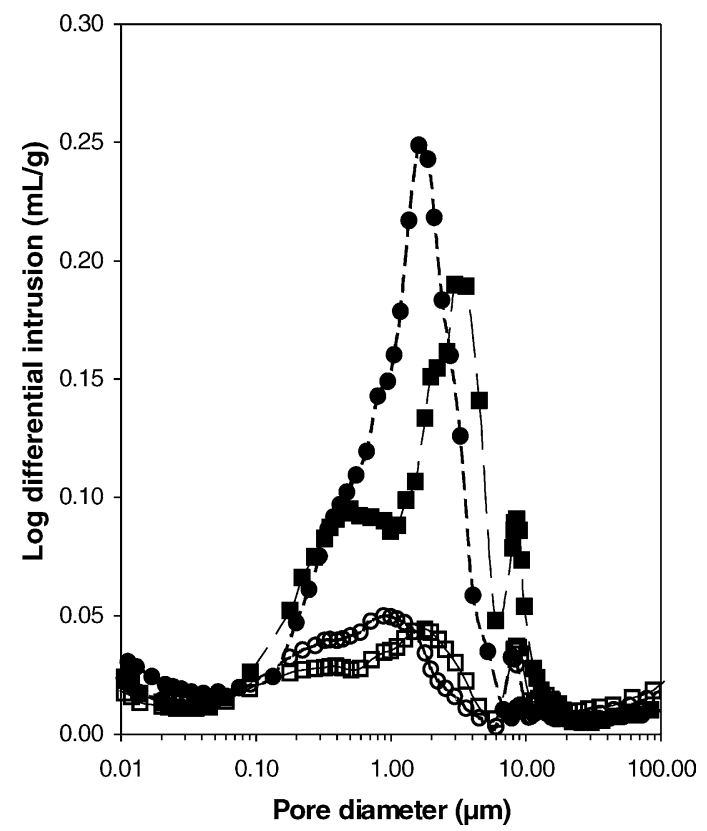

Fig. 2. Distribution of pore diameter as a function of the differential mercury intrusion - original pellets $\mathrm{PF} \# 1 \mathrm{~A}(\mathbf{\square}), \mathrm{PF} \# 1 \mathrm{~B}(\mathbf{\bullet})$, retrieved pellets PF\#1A ( $\square$ ) and PF\#1B (O).

\subsection{Compression of the pellets}

Examination of the two- and three-dimensions representations derived from the laser profilometry analysis of the upper surface of the tablets (Figs. 3 and 4, respectively), and the scanning electron microscopy of the same surface including the surface of fracture derived from the diametral compression of the tablets (Fig. 5) revealed that the particles remained as coherent individual units after compression process. Identification of each pellet unit composing the tablet was clearly observed. SEM micrographs and the 2D and 3D representations confirmed compression-induced changes in the shape of the units. During the process of compression the pellets were flatted in the same direction of the applied stress evidencing a lost of the original curvature of the spherical units. Such behaviour is in agreement with previous observations reported in the literature (Johansson et al., 1995, 1998; Johansson and Alderborn, 1996, 2001; Nicklasson et al., 1999a,b; Santos et al., 2004). The lost of sphericity was supported by the difference in the shape factor $e_{R}$ for pellets before and after compression $(P<0.001$ for pellets formulation $\underline{1 \mathrm{~A}}$ and $P=0.022$ for pellets formulation $\underline{1 \mathrm{~B}}, \alpha=0.05$ ). Such decrease in terms of shape factor was accompanied by an increase of the particle diameter (Feret diameter) that is a clear evidence of the shape flatness process which pellets were submitted during compression 

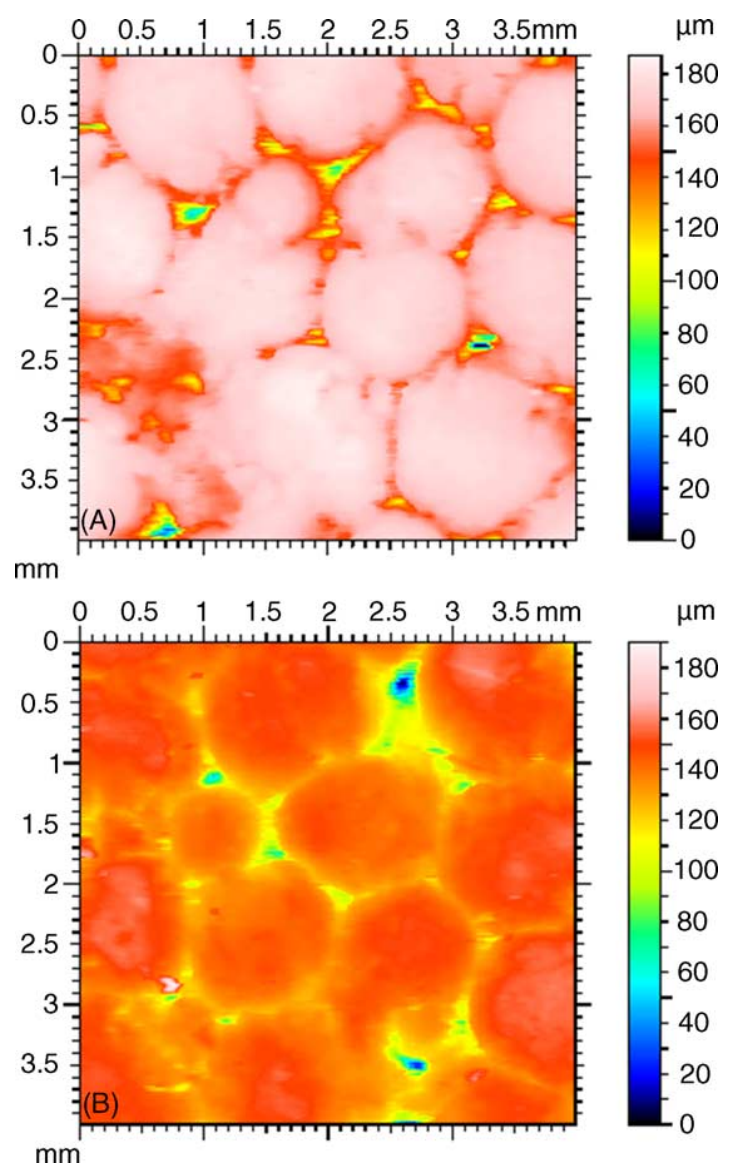

Fig. 3. 2D representation of top down view of scanned area of the upper surface of tablets made of pellets: A - tablets made of pellets PF\#1A; B - tablets made of pellets PF\#1B.

(Table 1).It was also observed that a volume reduction took place during the compression of the units. Xanthan gum pellets comprising diclofenac sodium experienced a porosity reduction of $65.5 \%$ while pellets comprising ibuprofen reduced their porosity in approximately $49 \%$. Compression led to the expulsion of the air entrapped in the cores in the form of porosity and was accompanied by the compaction of the units. Porosimetry studies revealed that both types of pellets experienced a marked reduction of the total pore volume and area and, consequently, a decrease in terms of pore diameter distribution (Table 2; Fig. 2). SEM micrographs of the cross-section of both types of pellet before compression revealed the presence of a large cavity in the centre of the pellet (Fig. 1). Similar observation is described in the literature (Juppo et al., 1997). The discussion of the genesis of such cavity was not within the scope of the present work, nevertheless its occurrence was an indication that possibly during the compression of the units, such cavity was diminished or even suppressed. The extensive reduction of the porosity of the pellets (Table 1) allied to the great reduction of the porosity parameters (Table 2) were conclusive in determining such observation.

The two types of pellets were considered of statistically different intragranular porosities $(P<0.001$, $\alpha=0.05$ ). In spite of that, no evidence of different mechanisms of compression besides deformation and densification was noticed. That is, fragmentation of the pellets was regarded as minimal or non-existent. Therefore, densification highly influenced the volume reduction of the bed of pellets after reposition and subsequent deformation of the units.

Pellets comprising diclofenac sodium were more porous, less susceptible to fracture and more sensitive to deformation and densification compared to those comprising ibuprofen. Comparatively, the structure of both types of pellets displayed close degree of compression although this value was slightly higher for pellets comprising diclofenac sodium (Table 1). It is believed that during compression, the primary particles within the pellet flowed in its structure to find new relative positions thus being affected by the porosity of the units. The size of the primary particle was one of the key factors affecting the above-mentioned reposition. Diclofenac sodium was, in the present study, the model drug of smallest particle size thus resulting in pellets more susceptible to reposition, of higher degree of compression and, furthermore, of higher densification.

\subsection{Compaction of pellets}

Xanthan gum pellets comprising diclofenac sodium were of higher intragranular porosity and resulted in tablets of tensile strength approximately four times higher than tablets made of xanthan gum pellets comprising ibuprofen (Table 3). Supposedly, the higher specific surface area of pellets formulation $1 \mathrm{~A}$ (Table 1) was an important factor that accounted for the better development of interparticle bonds thus being necessary an application of higher strength to cause the break of the tablet. The total porosity of the tablets of both formulations were of close values (Table 3). It is relevant 


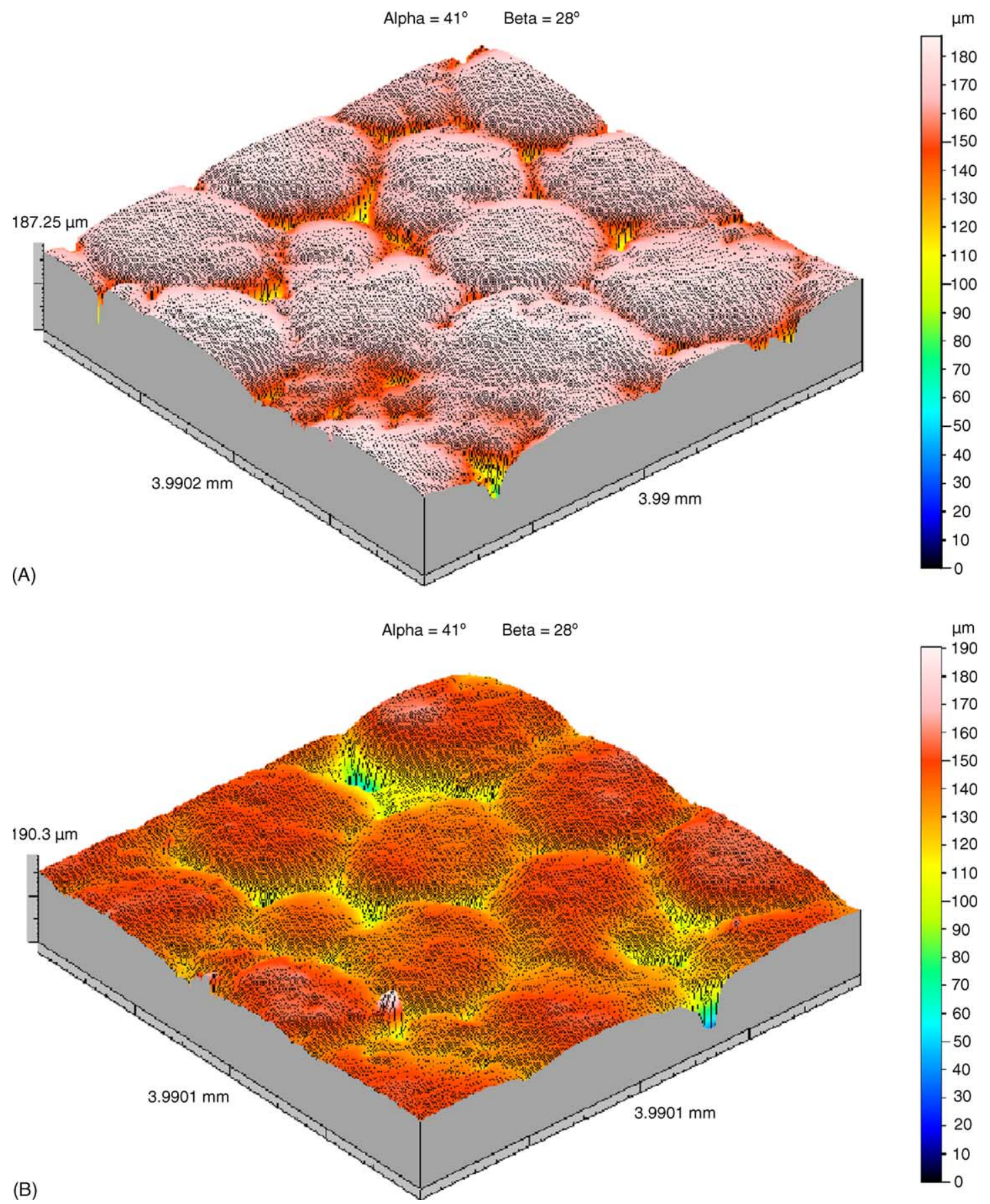

Fig. 4. 3D representation of top down view of scanned area of the upper surface of tablets made of pellets: (A) tablets made of pellets PF\#1A; (B) tablets made of pellets PF\#1B. 


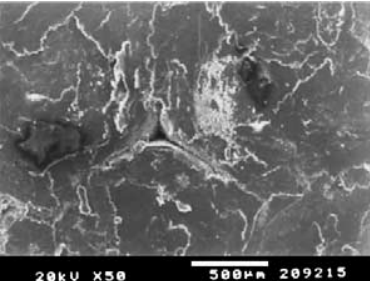

(A)

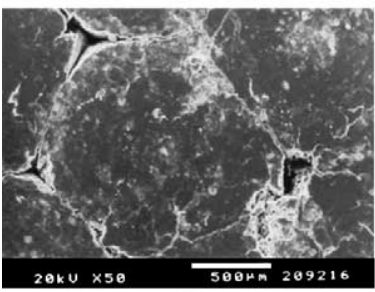

(C)

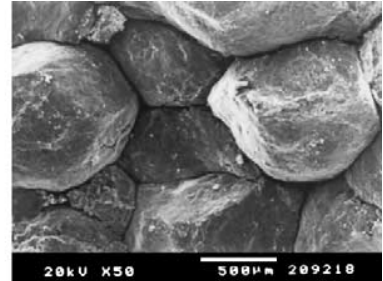

(B)

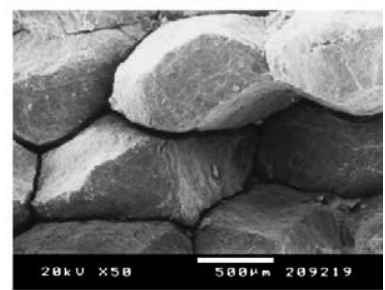

(D)
Fig. 5. SEM microphotographs - (A) upper surface view of tablet made of pellets PF\#1A; (B) fracture surface view of tablet made of pellets PF\#1A; (C) upper surface view of tablet made of pellets PF\#1B; (D) fracture surface view of tablet made of pellets PF\#1B. White bars denote $500 \mu \mathrm{m}$.

Table 2

Porosity parameters of active drug xanthan gum pellets

\begin{tabular}{llll}
\hline Pellets & $\begin{array}{l}\text { Total pore } \\
\text { volume }(\mathrm{mL} / \mathrm{g})\end{array}$ & $\begin{array}{l}\text { Total pore } \\
\text { area }\left(\mathrm{m}^{2} / \mathrm{g}\right)\end{array}$ & $\begin{array}{l}\text { Mean pore } \\
\text { diameter }(\mu \mathrm{m})\end{array}$ \\
\hline PF\#1A original & 0.228 & 6.836 & 0.133 \\
PF\#1A retrieved & 0.103 & 5.134 & 0.080 \\
PF\#1B original & 0.241 & 8.881 & 0.109 \\
PF\#1B retrieved & 0.099 & 6.204 & 0.064 \\
\hline
\end{tabular}

to point that the compression process of pellets formulation $\underline{1 \mathrm{~A}}$, which were of higher intragranular porosity and degree of densification, resulted in an extensive deformation of the units followed by an extensive decrease in terms of porosity thus leading to compacts of low porosity and high tensile strength. A different behaviour was noticed for pellet formulation $\underline{1 \mathrm{~B}}$ which were of lower intragranular porosity and degree of den-

Table 3

Physical characteristics of tablets made of drug active xanthan gum pellets

\begin{tabular}{llll}
\hline Tablets & Height $(\mathrm{mm})$ & $\begin{array}{l}\text { Total porosity } \\
(\%)\end{array}$ & $\begin{array}{l}\text { Tensile } \\
\text { strength }(\mathrm{MPa})\end{array}$ \\
\hline TF\#1A & $4.60(0.005)$ & $8.87(0.896)$ & $2.17(0.167)$ \\
TF\#1B & $4.89(0.006)$ & $9.85(1.121)$ & $0.54(0.088)$ \\
\hline
\end{tabular}

Mean value (standard deviation in brackets). sification than pellet formulation $\underline{1 \mathrm{~A}}$ and resulted in tablets of total porosity close to the former but much more susceptible to fracture.

Tensile strength of both types of pellets implied that pellets comprising diclofenac sodium were more brittle and less elastic than pellets comprising ibuprofen. In that case, for the water-soluble model drug diclofenac sodium, the crystallisation of the dissolved particles during the drying process of the wetted pellets resulted in a greater degree of close interparticulate contact hence less elastic and more brittle agglomerates (Dyer et al., 1994). Nevertheless, compression of pellets resulted in tablets of close degree of compressibility although pellets formulation $\underline{1 \mathrm{~A}}$ were slightly more susceptible to compression.

\subsection{Dissolution behaviour and drug release}

The release of diclofenac sodium or ibuprofen from pellets and tablets made of xanthan gum pellets was studied. The release of the model drugs from the two pellets formulations was immediate, reaching the totality in not more than $30 \mathrm{~min}$ in the case of diclofenac sodium xanthan gum pellets while $60 \%$ of ibuprofen was released from xanthan gum pellets after $1 \mathrm{~h}$ of dissolution test (Fig. 6). During the test the pellets absorbed water and displayed extensive swelling. Concomitantly, the pellets released their entire drug content due to the disruption of the wetted/swollen structure. Tablets made of xanthan gum pellets showed similar behaviour: penetration of the medium into the core followed by swelling of the structure. The integrity of the structure of tablets made of ibuprofen xanthan gum pellets was kept until $3 \mathrm{~h}$ of dissolution test. Right after that time the drug was promptly released as a result of complete disruption of the swollen structure. The release of diclofenac sodium from tablets made of pellets was slower and approximately $70 \%$ of the drug was released after $24 \mathrm{~h}$ of dissolution test. For the latter tablets, it was observed no disintegration of the dosage form into the forming units. Tablets maintained their structure as a monolithic system resembling a swollen sponge-like arrangement that slowed drug release over the experimental time.

Xanthan gum, the control release agent included in the formulations, is known to have the ability to hydrate very rapidly in addition to exhibit a great swelling index compared to other gums (Sujja-areevath et al., 1998). 


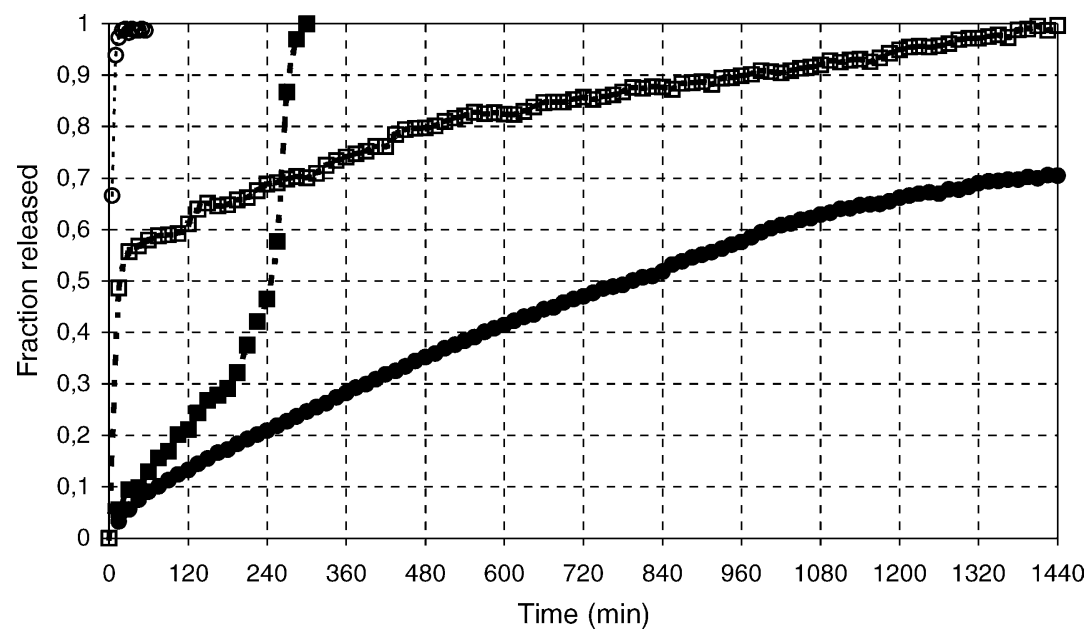

Fig. 6. Fraction of active drug released from pellets and tablets made of pellets: $(\bigcirc)$ pellets PF\#1A, $(\square)$ pellets PF\#1B, $(\bullet)$ tablets made of pellets PF\#1A, ( $\mathbf{\square})$ tablets made of PF\#1B.

It is speculated that drug release from tablets made of xanthan gum pellets was a result of hydration of the gum, which swelled extensively forming a barrier through which drug diffused. Erosion of the tablets was probably an important mechanism of drug release since gradual lost of size of the swollen tablets was noticed by visual inspection during dissolution.

As observed in a previous report (Santos et al., 2004), the visual inspection of the tablets during dissolution test revealed that the swollen tablets were constituted of swollen pellets on the surface that gradually eroded and were replaced by inner swollen pellets as the liquid medium penetrated into the core. In the case of tablets made of pellets comprising ibuprofen, the integrity of the swollen structure was maintained until the first hour of test. During that time, the model drug was gradually released, probably from the deaggregated pellets on the surface of the tablet. Soon after, small amounts of the drug were released until complete disruption of the swollen structure and consequent complete release of ibuprofen.

Although tablets made of pellets did not act as a multiparticulate system, the release of the model drug was sustained over the experimental time. To elucidate the possible release mechanism, analysis of drug release data derived from the dissolution tests were fitted to the exponential equation (5) (Korsmeyer et al., 1983)

$\frac{M_{t}}{M_{\infty}}=k t^{n}$ where $M_{t}$ is the amount of drug released at time $t, M_{\infty}$ the nominal total amount of drug, $M_{t} / M_{\infty}$ is the fraction of drug released within the range $0.1-0.6$ at time $t, k$ is the kinetic constant (in $t^{-n}$ ) that incorporates the properties of the polymeric system and the drug, and $n$ is the diffusional exponent of the drug release that is used to characterise the transport mechanism. In the case of tablets, $n=0.45$ for Case I (Fickian diffusion), $0.45<n<0.89$ for anomalous behaviour (non-Fickian transport) and $n \geq 0.89$ for Case II transport.

The release behaviour of tablets made of PF\#1A was anomalous providing release exponent $(n)$ value of $0.70\left(R^{2}=0.998\right)$. On the other hand, Case II transport characterised the release behaviour of tablets made of PF\#1B $\left(n=0.93 ; R^{2}=0.980\right)$. The fraction of drug released from tablet made of pellets $\mathrm{PF} \# 1 \mathrm{~B}$ is higher than that from tablet made of pellets PF\#1A since the beginning of dissolution. The overall release rate of the model drug from tablets TF\#1B is higher than that from tablets TF\#1A. Such observation is in accordance with the derived values of the kinetic constant $k$ (TF\#1A: $k=0.0047$; TF\#1B: $k=0.0025$ ). To confirm such observation and characterise the drug release, the mean dissolution time (MDT) was calculated according to Eq. (6) using the $n$ and $k$ values derived from Eq. (5) (Möckel and Lippold, 1993)

$$
\mathrm{MDT}=\left(\frac{n}{n+1}\right) k^{-1 / n}
$$




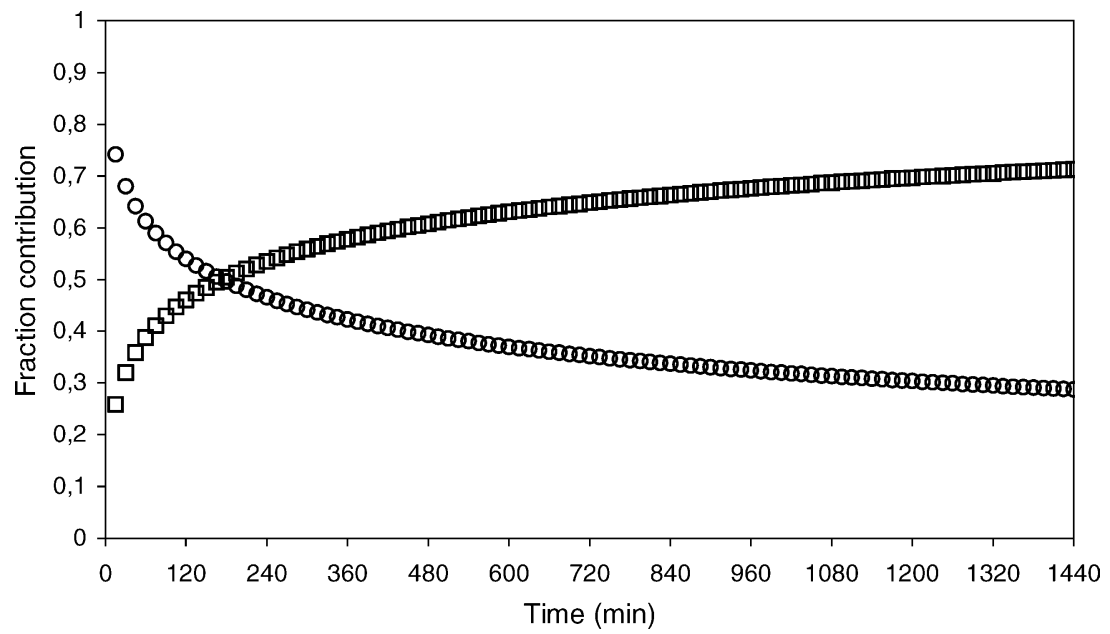

Fig. 7. Fraction contributions of the Fickian diffusion $(\bigcirc)$ and the erosion ( $\square$ ) mechanisms of diclofenac sodium released from tablets made of pellets.

The MDT of tablets made of pellets including diclofenac sodium was approximately 14 and $5 \mathrm{~h}$ for tablets made of pellets including ibuprofen.

Furthermore, to calculate the approximate contribution of the diffusional and relaxational mechanisms on the release of the model drug diclofenac sodium, data was fitted to the heuristic model (Eq. (7)) (Alfrey et al., 1966; Ritger and Peppas, 1987; Peppas and Sahlin, 1989)

$\frac{M_{t}}{M_{\infty}}=k_{1} t^{m}+k_{2} t^{2 m}$

The first term in the right-hand side of Eq. (7) refers to the Fickian contribution while the second term is the Case II erosional contribution. The coefficient $m$ is the purely Fickian diffusion exponent for a device of any geometrical shape that exhibits controlled release. The value of $m(0.43)$ for the tablets under investigation was derived from the plot of aspect ratio of the tablets (diameter/thickness) against diffusional exponent according to Peppas and Sahlin (1989). Drug release data was fitted to Eq. (7) by non-linear regression analysis using GraphPad Prism Version 3.00 for Windows (GraphPad Software, San Diego, CA, USA). The percentage of the drug released due to the Fickian mechanism $\left(F_{\text {mech }}\right)$ was calculated according to Eq. (8) whereas the ratio of relaxational $\left(R_{\text {mech }}\right)$ over Fickian $\left(F_{\text {mech }}\right)$ mechanisms contribution was calculated according to Eq. (9)
(Peppas and Sahlin, 1989)

$$
\begin{aligned}
& F_{\text {mech }}=\frac{1}{1+\left(k_{2} / k_{1}\right) t^{m}} \\
& \frac{R_{\text {mech }}}{F_{\text {mech }}}=\frac{k_{2}}{k_{1}} t^{m}
\end{aligned}
$$

The estimated contributions of the two mechanisms for tablets made of pellets PF\#1A are shown graphically in (Fig. 7). Fickian diffusion was predominant but decreased after the first $3 \mathrm{~h}$ of dissolution while polymer erosion gradually increased and became the predominant mechanism for the rest of dissolution time. Such behaviour is well explained by the increase of thickness of the viscous gel layer around matrix that created a longer path length for diffusion which was followed by polymer chain relaxation, disentanglement and erosion (Sujja-areevath et al., 1996, 1998).

\section{Conclusion}

Laser profilometry analysis was a useful tool for the characterisation of the mode of compaction of pellets. The conjunction of the profilometry analysis with the derived information from the visual inspection of the SEM micrographs confirmed that permanent deformation of the pellets was the most relevant mechanism involved in the compression of the units. Although some incidence of fragmentation of the pellets was noticed, 
it only occurred in very little extension therefore could be regarded as non-existent. Densification was also regarded as a relevant mechanism of compression since the visual examinations and the physical analysis implied its occurrence. In spite of pellets were considered of different porosities they exhibited similar compression mechanisms. Permanent deformation and densification of nearly spherical units were confirmed as the most important mechanisms involved during compression process.

Disruption of the agglomerate structure was reported and believed to be the result of the excessive swelling of the gum at the concentration of $16 \%$ (w/w). Pellets' matrix integrity was destroyed in the first hour of dissolution. Similar behaviour was noticed for tablets of pellets comprising ibuprofen as the model drug, matrix integrity was compromised and destroyed after approximately $3 \mathrm{~h}$ of dissolution test. Such occurrence was possibly the result of increased total porosity of the tablet due to the drug release coupled with swelling of the gum.

Tablets of pellets comprising xanthan gum did not function as multiparticulate system. Nevertheless drug release control was achieved specifically in the case of tablets made of pellets including diclofenac sodium as the model drug. Non-Fickian transport mechanism characterised drug release from these tablets. Tablets of pellets including ibuprofen released the model drug in bimodal fashion and was characterised as Fickian diffusion mechanism. The approximate contribution of the mechanisms of release approach introduced by Peppas and Sahlin (1989) was a useful tool to further characterisation of drug release. According to this approach, for tablets of pellets comprising diclofenac sodium, diffusion was the predominant mechanism of drug release during the first $3 \mathrm{~h}$ of dissolution then relaxational mechanism dominated until the end of the test.

\section{Acknowledgments}

H. Santos would like to thank Fundação Para a Ciência e a Tecnologia, Portugal, for the financial support (BD/18171/98) and The School of Pharmacy, University of London for the physical characterisation of the pellets. Special thanks to Professor Dr. Fridrun Podczeck at The School of Pharmacy, University of London, for the technical support and to Mr. Adam
Donoghue at Solarius Development Inc. for the laser profilometry analysis of the tablets.

\section{References}

Alfrey Jr., T., Gurnee, E.F., Loyd, W.G., 1966. Diffusion in glassy polymers. J. Polym. Sci. Part C 12, 249-261.

Çelik, M., 1994. Compaction of multiparticulate oral dosage forms. In: Ghebre-Sellassier, I. (Ed.), Multiparticulate Oral Drug Delivery. Marcel Dekker, New York, pp. 181-216.

Dyer, A.M., Khan, K.A., Aulton, M.E., 1994. Effect of the drying method on the mechanical and drug release properties of pellets prepared by extrusion-spheronisation. Drug Dev. Ind. Pharm. 20, 3045-3068.

Fell, J.T., Newton, J.M., 1970. Determination of tablet strength by diametral-compression test. J. Pharm. Sci. 59, 688-691.

Ingani, H.M., Moës, A.J., 1998. Utilisation de la gomme xanthane dans la formulation des matrice hydrophiles. STP Pharma 4, 188-195.

Johansson, B., Alderborn, G., 1996. Degree of pellets deformation during compaction and its relationship to the tensile strength of pellets formed of microcrystalline cellulose pellets. Int. J. Pharm. 132, 201-220.

Johansson, B., Alderborn, G., 2001. The effect of shape and porosity on the compression behaviour and tablet forming ability of granular materials formed from microcrystalline cellulose. Eur. J. Pharm. Biopharm. 52, 347-357.

Johansson, B., Wikberg, M., Ek, R., Alderborn, G., 1995. Compression behaviour and compactability of microcrystalline cellulose pellets in relationship to their pore structure and mechanical properties. Int. J. Pharm. 117, 57-73.

Johansson, B., Nicklasson, F., Alderborn, G., 1998. Effect of pellet size on degree of deformation and densification during compression and on campactability of microcrystalline cellulose pellets. Int. J. Pharm. 163, 35-48.

Juppo, A.M., Hellén, L., Pullinen-Strander, V., Kalsta, K., Yliruusi, J., Kristoffersson, E., 1997. Application of mercury porosimetry in evaluation of extrusion-spheronisation process. Eur. J. Pharm. Biopharm. 44, 205-214.

Korsmeyer, R.W., Gurny, R., Doelker, E., Buri, P., Peppas, N.A., 1983. Mechanisms of solute release from porous hydrophilic polymers. Int. J. Pharm. 15, 25-35.

Möckel, J.E., Lippold, B.C., 1993. Zero-order drug release from hydrocolloid matrices. Pharm. Res. 90, 1066-1070.

Nicklasson, F., Jahansson, B., Alderborn, G., 1999a. Occurrence of fragmentation during compression of pellets prepared from a 4 to 1 mixture of dicalcium phosphate dihydrate and microcrystalline cellulose. Eur. J. Pharm. Sci. 7, 221-229.

Nicklasson, F., Jahansson, B., Alderborn, G., 1999b. Tabletting behaviour of pellets of a series of porosities - a comparison between pellets of two different compositions. Eur. J. Pharm. Sci. 8, 11-17.

Peppas, N., Sahlin, J., 1989. A simple equation for the description of solute release. III. Coupling of diffusion and relaxation. Int. J. Pharm. 57, 169-172. 
Podczeck, F., Newton, J.M., 1994. A shape factor to characterise the quality of spheroids. J. Pharm. Pharmacol. 46, 82-85.

Ritger, P.L., Peppas, N.A., 1987. A simple equation for description of solute release from swellable devices. J. Controll. Rel. 5, 37-42.

Salako, M., Podczeck, F., Newton, J.M., 1998. Investigation into the deformability and tensile strength of pellets. Int. J. Pharm. 168, 49-57.

Santos, H., Veiga, F., Pina, M., Podczeck, F., Sousa, J., 2002. Physical properties of chitosan pellets produced by extrusionspheronisation: influence of formulation variables. Int. J. Pharm. 246, 153-169.

Santos, H., Veiga, F., Pina, M., Sousa, J., 2004. Compaction, compression and drug release characteristics of xanthan gum pellets of different compositions. Eur. J. Pharm. Sci. 21, 271-281.

Shipway, P.H., Hutchings, I.M., 1993. Fracture of brittle spheres under compression and impact loading. II. Results for lead-glass and sapphire spheres. Phil. Mag. A67, 1405-1421.

Sujja-areevath, J., Munday, D.L., Cox, P.J., Khan, K.A., 1996. Release characteristics of diclofenac sodium from encapsulated natural gum mini-matrix formulations. Int. J. Pharm. 139, 53-62.

Sujja-areevath, J., Munday, D.L., Cox, P.J., Khan, K.A., 1998. Relationship between swelling, erosion and drug release in hydrophilic natural gum mini-matrices formulations. Eur. J. Pharm. Sci. 6, 207-217.

Talukdar, M., Kinget, R., 1997. Comparative study on xanthan gum and hydroxypropylmethyl cellulose as matrices for controlledrelease delivery. II. Drug diffusion in hydrated matrices. Int. J. Pharm. 151, 99-107.

Talukdar, M., Michoel, A., Rombaut, P., Kinget, R., 1996a. Comparative study on xanthan gum and hydroxypropylmethyl cellulose as matrices for controlled-release drug delivery. I. Compaction and in vitro drug release behaviour. Int. J. Pharm. 129, 233-241.

Talukdar, M., Vinckier, I., Moldenaers, P., Kinget, R., 1996b. Rheological characterization of xanthan gum and hydroxypropyl- methyl cellulose with respect to controlled-release drug delivery. J. Pharm. Sci. 85, 537-540.

Talukdar, M., Plaizier-Vercammen, J., 1993. Evaluation of xanthan gum as a hydrophilic matrix for controlled-release dosage form preparations. Drug Dev. Ind. Pharm. 19, 10371046.

Wade, A., Weller, P.J., 1994. Handbook of Pharmaceutical Excipients, 2nd ed. The American Pharmaceutical Association (USA) and The Pharmaceutical Press, England, pp. 562-563.

Wikberg, M., Alderborn, G., 1990a. Compression characteristics of granulated materials. II. Evaluation of granule fragmentation during compression by tablet permeability and porosity measurements. Int. J. Pharm. 62, 229-241.

Wikberg, M., Alderborn, G., 1990b. Compression characteristics of granulated materials. III. The relationship between air permeability and mechanical strength of tablets of some lactose granulations. Int. J. Pharm. 63, 23-27.

Wikberg, M., Alderborn, G., 1991. Compression characteristics of granulated materials. IV. The effect of granule porosity on the fragmentation propensity and the compactability of some granulations. Int. J. Pharm. 69, 239-253.

Wikberg, M., Alderborn, G., 1992a. Compression characteristics of granulated materials. V. Mechanical properties of individual granules, assessed by diametral compression, in granulations with different volume reduction behaviour. STP Pharm. Sci. 2, 313-319.

Wikberg, M., Alderborn, G., 1992b. Compression characteristics of granulated materials. VI. Pore size distribution, assessed by mercury penetration, of compacts of two lactose granulations with different fragmentation propensities. Int. J. Pharm. 84, 191-195.

Wikberg, M., Alderborn, G., 1993. Compression characteristics of granulated materials. VII. The effect of intragranular binder distribution on the compactability of some lactose granulations. Pharm. Res. 10, 88-94. 